\title{
Priority Changes for Strengthening Women's Role as Producers, Processors and Providers of Food and Nutrition
}

\author{
Amita Shah
}

\begin{abstract}
The mutual dependence between access to food, nutrition and women's agency brings women to the centre stage of the discourse on food justice. The contemporary discourse needs to engage with wideranging issues pertaining to the agrarian crisis, feminisation, and new institutional arrangements facing the sector. Prima facie, this would imply changing the priorities right from research and extension, through resource allocation and crop choice, to subsidies and incentives at local and national levels. As an important prerequisite, the growth approach for agriculture is to be geared towards valuing women's work in a holistic framework. This, essentially, would call for the mobilisation, consolidation and strengthening of the right forces working within communities and groups of people committed to working towards the common goal of a gendered growth in agriculture and food security in India. Civil society organisations may take a lead in anchoring the process.
\end{abstract}

\begin{abstract}
1 Introduction
Historically, women in India have been major contributors to the production, processing, and provisioning of food and nutrition at national as well as household levels. Their roles, however, may vary significantly across class, caste, culture and the socioeconomic-climatic contexts that shape actual access to food and nutrition. Conversely, the issue of food and nutrition continues to shape the world of women's lives and work within and outside the domestic spheres. The mutual dependence between access to food and nutrition and women's agency thus brings women to the centre stage of the discourse on food justice. This would imply that the issues of production, processing and provisioning should be seen through the gender lens, which in turn may require adjustments to or reorganisation of the food and nutrition sector. This is at variance with the perspective of gender 'mainstreaming', which seeks to consolidate women's contributions within the existing structure of production, distribution and access to food. The contemporary approach to gender 'mainstreaming' is running parallel with a process of 'feminisation', which on the one
\end{abstract}

hand signifies increasing numbers of women workers in the sector and on the other implies their adverse incorporation in the sector. ${ }^{1}$ Fostering a gendered approach to food and nutrition thus poses a formidable challenge where the vision is (or ought to be) to strengthen women's agency without allowing the feminisation process to creep in.

The contemporary discourse, therefore, needs to engage with the larger realities of the agrarian crisis, patterns of feminisation, and the new opportunities as well as the institutional arrangements essential for attaining women's centrality in the food and nutrition sector. A comprehensive approach such as this is necessary owing to the multiple disadvantages stemming from women's subordinate position in a household setting. In addition, women are also victims of the larger processes of agrarian crisis manifested through the shrinking size of landholdings, degraded soils and water resources, declining accessibility of seeds and other inputs, distorted market incentives for crop choice and technology, growing labour shortage, 
and mechanisation in agriculture. Feminisation of Indian agriculture has taken shape within this larger reality; crafting a fresh approach for women in agriculture thus assumes special significance. This article briefly discusses the context for a gendered approach to food and nutrition and seeks to identify critical policy interventions, at macro as well as micro levels, for setting up the right kind of priorities.

\section{Contextualising women's role} 2.1 Women farmers and land rights: From unpaid labourers to entrepreneurs?

Women have been increasingly recognised as the future faces of Indian farmers (Shah and Kumar Roy 2012; Vepa 2005; Krishna Raj and Shah 2004). According to recent estimates from the 64 th round of the National Sample Survey Office (NSSO), women accounted for 38.51 per cent of all rural workers engaged in the primary sector during 2007-08. ${ }^{2}$ They constitute a significantly large proportion (about $80-83$ per cent) of all women workers in rural areas whereas 63-66 per cent of rural male workers are engaged in this sector. Women also play a significant role in the various allied activities; according to the time use survey covering six states in the country during 2000, women spent almost equal amounts of time on crop cultivation and allied activities. Unfortunately they receive payment for only 60 per cent of the time they spend in agriculture, as a substantial part of their work is likely to be on the family farms (Vepa 2005).

\subsubsection{Access to land}

Few women own land or have the financial resources to lease land on their own (Agarwal 2003, 1994). Women workers who are counted as 'cultivators' in national statistics tend to be largely unpaid workers on family farms. In 2004-05, 36 per cent of women farmers overall, and 39 per cent among marginal landholding households, were counted as unpaid workers on family farms (NCEUS 2010). Providing ownership of land among women is an uphill task experiencing severe constraints on the social, economic, and legal fronts. In very detailed documentation, Bina Agarwal has described the various legal constraints faced by Indian women in claiming their rights on land. Agarwal (1994) noted that among most religious groups in India, women are vested with smaller shares than men in property inheritance (p. 246). Whereas the Hindu Succession Act (1956) provides for sons and daughters to inherit equal shares in property owned by the nuclear family, the same does not hold true for property owned by the extended family. Some of the states in southern parts of India have enacted laws to make provisions of the Act applicable to the ancestral property. Also amendments to the Act have reduced, but not eliminated, the pre-existing gender inequalities in property rights (p. 214). The same holds true for several other religious groups in the country. Apart from inheritance, laws regulating land reforms also impinge upon women's ownership of or access to land.

The struggle for women's land rights, however, has to go beyond the legal realm as much of the resistance stems from sociocultural norms influencing the actual implementation of laws. This suggests a long and a difficult trajectory before realising the vision of equal rights for women in property in general and land in particular. Joint titles to land for married women (with their husband) may therefore work as a minimalist agenda in the meantime.

\subsubsection{Workforce participation}

The pattern of feminisation of agriculture seems to have been shaped by a number of changes in the labour markets, both rural and urban. Some of these include:

- rural men having started to find jobs in nonagricultural activities outside rural areas;

- women having taken up a number of tasks that were traditionally performed by men;

- the declining size of landholdings rendering a large proportion of farms unviable and left for women to manage;

- the agrarian crisis requiring more women to undertake poorly paid work in non-profitable activities and having to bear the additional burden of the overall downturn in the economy without gaining additional autonomy since men have not been able to completely pull themselves out of agriculture;

- withdrawal of women workers perhaps in the wake of non-viability of farming on the one hand and increased earnings from nonagricultural activities on the other; and

- mechanisation of agricultural operations driven by a combination of factors like crop diversification, productivity enhancement, seasonal labour shortages, withdrawal of labour (male and female) from agriculture, etc. 
It appears that this complex cobweb of factors has led to blurring of the gender differentiations and power relations thereby creating new compacts and realities facing women and men in agriculture.

The contemporary discourse on women's role in agriculture therefore needs to be located within the complex reality where women are assuming increasing space as workers and producers without gaining effective control over not only productive resources and decision-making, but also over risks and opportunities associated with farming. Insofar as male members of the households are not in a position to make a complete shift out of agricultural operations mainly because of the non-availability of more productive jobs in the non-farm sector - the expected impacts of feminisation on women's empowerment may, at best, be very gradual and subtle rather than being substantial and pronounced. For the critical issue is who takes the ultimate responsibility for the outcomes that get shaped within an environment of low profitability and/or high-risk agriculture. Women's rights over land and other productive resources may help them face these situations better than otherwise but ownership of land per se may not play out as a simple and straightforward device for empowering women as farmers.

This complex reality prompts us to explore a somewhat fresh ground for women's empowerment in agriculture. It seems that instead of women's (as against men's) control over resources and decision-making, a more appropriate perspective is that of jointness, expansion of negotiating space, and complementarity of work as well as responsibilities between men and women in managing a fairly diverse portfolio of employment and income at household level. This may sound a little regressive but, perhaps more real, hence relevant. For the conventional approach to 'mainstreaming' of women ends up not only creating an additional work burden for women, but also giving them the huge responsibility of lifting agriculture out of its deep crisis owing to a number of factors beyond the control of individual farmers - men or women. Mitigating the agrarian crisis thus becomes an important prerequisite for gender empowerment.

2.2 Resource regeneration and participatory institutions Regeneration and conservation of natural resources is an important precondition for lifting agriculture out of the crisis, as noted earlier. Public investment in land, water and forests at different levels from basin to micro-watersheds holds the key to resource regeneration thereby contributing to enhanced productivity in agriculture. Community participation is an important element in the process of sustainable use of natural resources with equitable sharing of the benefits. The contemporary policies thus mandate participation of community members, including women and other socially disadvantaged groups, in some of the larger initiatives like the Integrated Watershed Management Programme (IWMP), Participatory Irrigation Management (PIM), Joint Forest Management (JFM) and fishing cooperatives, provision of water and sanitation, etc. (Shah 2007).

While steps in the right direction, these policy initiatives are yet to result in robust communitybased institutions for resource management as these institutions often face enormous challenges in the face of the existing socioeconomic-political hierarchies where elite capture and financial irregularities are common features. Experience till now suggests that women obtaining a legitimate space as active members, participants and important stakeholders in benefit-sharing is a tall order. To a large extent, women's representation on the elected bodies of local selfgovernance, and also the massive expansion of women's self-help groups (SHGs) for saving and credit services share similar plights.

There are, however, a number of real-life examples where women have made significant inroads into public spaces and have emerged as powerful groups working for the agenda of sustainable and equitable development in agriculture (Krishna 2007;

Planning Commission 2011). Kudumbasree in

Kerala and SHGs in some of the states in southern India are among a large number of exemplary initiatives of women's groups contributing to women's collective identity and empowerment.

All these would mean swimming against the social norms and hierarchies. Also participation in such institutions requires an investment of time (Vepa 2005) which eventually may result in women's empowerment. It is thus imperative that long-term institutional support is extended to women's groups and collectives and helps them emerge as an important source for the reformed agenda. 


\subsection{Women's role as providers of food and nutrition}

Women, in most parts of the world, perform a critical role in providing food and nutrition. Whereas the link primarily stems from the biological phenomenon, it tends to get reinforced by the sociocultural norms prevailing in most societies - past and present. Building further on this organic link between women and food-nutrition security, the conventional gender discourse has laid special emphasis on women's autonomy in food production, control over disposable income, and changing the sociocultural norms that shape intra-household discrimination in food consumption.

A close examination of a number of real-life situations, however, may suggest that income alone may not be adequate to overcome the calorie-micronutrient deficiencies among the vast majority of the population. Clearly, access to health services, drinking water, the level of hygiene in living conditions, and sociocultural norms matter a lot in determining nutritional outcomes. The importance of non-income variables gets further sharpened when it comes to improving women's nutritional status as they suffer from multiple discrimination, not only in terms of food intake, but also in terms of access to health care and hygiene facilities. This is especially so at critical stages of their reproductive functions when they require special food as well as other support (Shah and Pattnaik 2012).

Of late the poor, including women, have been confronted with a number of compelling new consumption requirements like transport, education, fuel and drinking water, and also social expenses. It is likely that all these may take precedence over some of the basic requirements such as food, health and sanitation services. Whereas much of the increased pressure on household consumption expenditure may be due to the state's withdrawal from provision of various basic amenities, the social fabric also seems to have undergone simultaneous changes, with gradual erosion of community institutions and mutual help. The recent spurt in food inflation may have further altered the composition and priorities of a household's consumption basket. All these may also influence current gender dynamics.

Whereas raising the income threshold to a fairly high level is an important precondition for addressing the issue of food and nutritional insecurity, improving the quality as well as the composition of the food basket may go a long way to improving the situation. This may call for addressing a wide range of issues like crop choice, input use, and preparation of food; women ought to have a significant say in all these decisions.

\section{Reshaping macro policies and priorities} 3.1 Agrarian crisis: The policy approach

The first and foremost challenge for future policy is to address the various issues pertaining to agrarian distress. The draft approach for the 12th Five Year Plan envisages a comprehensive approach that lays special emphasis on increasing productivity of foodgrain production on the one hand and promoting crop diversification on the other. Attaining these objectives, however, may require a fairly wellcalibrated strategy that essentially addresses the issues of (1) natural resource sustainability, and (2) overcoming the constraints faced by disadvantaged farmers that include small landholdings, socially discriminated groups including women, and regions facing ecological challenges (such as dry land, flood susceptibility, coastal and hilly regions) with low agronomic potential (Planning Commission 2011). ${ }^{4}$

The disadvantages emanating from shrinking farm sizes and non-viability of farming get further compounded where the plot cultivated is not owned, and therefore cannot serve as collateral for credit or provide security of tenure. ${ }^{5}$ Whereas a number of innovative mechanisms have been discussed recently, overcoming the size disadvantage calls for new institutions and organisational arrangements (Agarwal 2010). There is a sense of urgency here as absence of these may prove detrimental not only to food production and food security, but also to women farmers and workers engaged in this unviable economic activity.

On the issue of overcoming social as well as ecological constraints, the recent policies seek to strengthen ongoing efforts for regeneration of land, water, forest and also pastures as well as wetlands. In a major departure from past policies that had rested mainly on irrigation-led agriculture, the 12th Five Year Plan is likely to shift attention to rainfed areas, especially in the central-eastern states. Apparently, this opens up special opportunities for growth in agriculture 
and allied sectors, based on diversified farming systems where the cultivation of vegetables, of nutritious fruits in home gardens, the production of milk, fishing, and livestock-rearing deserve special attention (Shah 2005). It is encouraging that women will have an increasing role to play in steering this shift in the composition as well as locus of growth in agriculture and allied sectors as demonstrated by the following points:

- women already have a larger presence in the diversified sectors noted above;

- men are already forced to look for employment opportunities outside agriculture and rural economies;

- sustainable agriculture is likely to be more 'knowledge'-intensive than 'input'-intensive, where the traditional knowledge of farmers both men and women - may assume special significance;

- the revival of farming systems may also bring into play some of the food crops (like pulses and oilseeds and coarse grains) and other products (such as milk, fish and fruits/nontimber forest produce) that may have special nutritional value;

- many of the new activities may involve collective action not only for management of Common Property Resources (CPRs), but also for processing, marketing, and accessing credit.

This implies that the restructuring of production for higher growth in agriculture should simultaneously address the issues of productivity, economic viability, and gender equity. This in turn involves working on issues of not only resource ownership, but also consolidation of landholdings, efficient use and management of land and water resources, appropriate choice of crops and technology, adequate price incentives, and institutional support. Women farmers should be at the centre of these policy initiatives in partnership with men, who may be absent and yet remain important stakeholders in overcoming the crisis in agriculture.

\subsection{Beyond women's work and income}

A number of good initiatives have been taken up for promoting household food production, developing wasteland for food and fodder production, organising seed and grain banks, providing credit through women's collectives and, above all, conducting special extension programmes for women farmers. The policy approach for the 12th Five Year Plan may move further in this direction in the light of recommendations by the working group on 'Disadvantaged Farmers, Including Women' (Planning Commission 2011). While these are useful interventions that indeed have intrinsic value for creating a gendered perspective on agriculture, it is not clear how effective they could be in the absence of a systemic change in production and distribution within the food sector in the country.

The pertinent issue is whether increased income for women as farmers or wage earners can necessarily ensure an increase in women's access to food and nutrition. The evidence, at best, may be mixed. What has, however, emerged fairly clearly is that the growing uncertainties and fluctuations in agricultural growth and farm income may well prove detrimental to food intake for all poor people, especially women, as noted earlier. This has been substantiated by a number of studies that looked into the coping mechanisms adopted by workers in the informal sector, where cutting down on food consumption and an increased work burden on women clearly emerged as the most important strategies adopted by many households trapped in the financial crises of recent years. Sectoral diversification thus becomes the hallmark survival strategy among many men and women engaged in the overcrowded agricultural employment scenario. Unfortunately, there are only limited opportunities for non-farm employment, especially for women (Himanshu 2011). In any case, sectoral diversification per se may not automatically improve women's plight as producers, processors and providers of food and nutrition.

Similarly, women's control over income may not ensure adequate food and nutrition for their family members though it may bring relatively better health and nutritional outcomes as compared to households where women did not have control over income and/or any say in decision-making processes. This has been borne out by a number of studies in India and in other developing economies (Meinzen-Dick et al. 2010). ${ }^{6}$ Overall, the evidence suggests that women bear a double burden of food insecurity or malnourishment, first for being part of a poor household and second for being victims of culturally contextualised discrimination in food intake. 
Changing social norms is often difficult and time-consuming. It is therefore argued that intra-household discrimination against girls and women is unlikely to be addressed by statutory provisions or punitive measures for the male head of the household. Whereas awarenessgeneration helps shape social norms in the long run, that in the absence of overall improvement in income and availability of food, may not prevent the current generation suffering from severe food and nutrition deficiencies. The mother's health and nutritional status matter a lot in determining nutrition for children.

Attending to the mother's requirements for food, nutrition and basic health services thus assumes special significance.

To reiterate the main argument, it may be noted that women's control over income is important, but in the absence of adequate availability of food at the household level, this may not be a sufficient condition for ensuring food and nutritional security among poor people and women. Equally important is access to safe drinking water and basic health and hygiene services for effective conversion of food intake into improved nutritional status. Macro-level policies for promoting food production, especially among poor and women farmers, along with state-supported distribution systems for food, drinking water and health and hygiene services are thus extremely important.

\subsection{Public provision of food}

Public distribution of food (Public Distribution System - PDS) has a long history in India though with a dismal performance; getting into the details however, is beyond the scope of this article. The relevant point here is the almost complete absence of women in the PDS, either as managers and/or as primary beneficiaries, despite the wellrecognised organic link between women and food provision - a point already noted earlier. Some of the special nutritional programmes such as midday meals and fortification of food for schoolchildren have at least partly recognised the importance of the role of women's self-help groups. But much more needs to be accomplished to realise the full potential of these groups in the public provision of food and nutrition.

A number of successful experiments in different parts of the country suggest that women's collectives could work fairly effectively along the entire supply chain right from cultivation of foodgrains, through their processing, to seed storage as well as food stocks, and also distribution. The forthcoming Right to Food bill may pave the way for women's rightful engagement in managing food distribution, which may also work as a protective mechanism against the severe food inflation, sustained over a long period of time, despite good food harvests in the country. The group approach may entail a number of institutional arrangements such as producers' companies, contract farming, group entrepreneurship, etc., to strengthen women's presence and bargaining capacity in various marketing functions.

A similar approach could be adopted for producing, processing and providing some of the nutrition-rich products such as small millet, milk, fish, vegetables and fruits, medicinal herbs, and other minor forest produce. As noted earlier, women have a significant presence in most of these activities. The need therefore is to make these women and their collectives emerge as viable entrepreneurs within a vertically integrated supply chain. The two most important preconditions for realising such a shift are (1) institutional support on a sustained basis, and (2) positive discrimination to create spaces for sound women's collectives.

\section{Recent policy initiatives for setting the priorities}

The foregoing analysis highlights the importance of a macro-level policy framework to create a conducive environment within which the gendered perspective on agriculture and food-nutrition security may be meaningfully operationalised. This referred to three important pillars of the macro policy environment: promoting food production in a sustainable and equitable manner; enhancing women's autonomy; and access to public provision of food, drinking water and basic health and hygiene services. Given this backdrop, specific measures that could be taken up on a priority basis could be listed as follows:

1 Incentivise land titles to women and joint ownership between husband and wife, and also facilitate group leasing and purchase of land by reviving and restructuring institutions such as the land bank.

2 Promote women's labour collectives and cooperative farming in order to overcome the problem of small landholdings. 
3 Engage labour collectives to undertake soil and water conservation measures, especially on marginal and small farms. This could be dovetailed with ongoing schemes like watershed development, employment guarantees, afforestation, pasture development, rejuvenation of wetlands for fishery, etc.

4 Promote sustainable practices by adopting the farming systems approach and involve women farmers in development and dissemination of the appropriate farm practices. Exposure tours and agricultural fairs should be special attractions where women could be given free entry.

5 Improve work conditions in non-farm employment, especially among men, to reduce their stress in simultaneously looking after multiple occupations, including on-farm activities. This may enhance autonomy for women farmers and joint decision-making processes.

6 Provide price as well as non-price incentives for the cultivation of coarse cereals, pulses and oilseeds, and promote allied activities like livestock farming, fishing, homestead plantations, cultivation of fruit and vegetables, poultry farming, growth of medicinal plants, etc.

7 Reduce women's work burden by pooling labour, along with appropriate mechanisation aiming particularly at the reduction of drudgery on the one hand and waste on the other.

8 Involve women's groups along the entire supply chain right from resource regeneration, seed production and storage through to distribution of foodgrains via the Public Distribution System by promoting producer companies, contract farming, and group enterprises, along with the requisite institutional support.

9 Accord special priority to women's groups to take up processing and marketing of various agri-products; this should be supported by longterm institutional handholding. Multilayered institutions and federations may help break the scale barriers of such enterprises.

10 Link enterprises having public distribution outlets managed by women with special nutrition programmes.

11 Ensure the availability of safe drinking water and basic health and hygiene services.

12 Strengthen midday meal and other nutritional programmes for young girls and lactating mothers. Improve water and sanitation facilities for girls in school premises.

\section{Conclusion}

By way of summary:

- The gendered gap in nutrition cannot be bridged merely by ensuring the greater presence of women as producers, workers, and decision-makers in the sector.

- Food and nutrition security for women also requires systemic shifts in the various factors influencing production, distribution, and access to food among poor households.

- Changes must be made to macro policies relating to resource use, subsidies, trade, public distribution, and the right to food.

- Supporting collectives led by women in all three spheres (production, processing and provisioning) may simultaneously help achieve the twin objectives of food-nutrition security and gender equity.

- Creating new institutions and giving them long-term support is critical for attaining a systemic shift in the agricultural sector.

- Affordability will be improved by reducing food inflation.

- Women must be brought to the centre of the food supply chain covering production, storage, and distribution.

Attaining these would necessitate, inter alia, changing priorities right from research and extension, through resource allocation and crop choice, to subsidies and incentives at local and national levels. The next round of agricultural growth should therefore lead not only to women's increasing contribution to the workforce and training for skill formation, but should also eventually create conditions that are more gender-equitable in the sense noted above. This could be achieved only when the entire approach to agricultural growth (or development) is geared towards valuing women's work in a holistic context. Spearheading a paradigm shift such as this may not be attained merely by changing policy priorities, as translating policies into reality may involve working against sociocultural and legal constraints. This requires mobilisation, consolidation and handholding of the right forces working within communities and groups of people committed to work toward the common goal. Civil society organisations may have to take the lead in anchoring the process, aided by policy reforms and market development, to foster a gendered growth in agriculture and food security in the future. 


\section{Notes}

1 It has been noted that 'Precisely at this juncture when agriculture is "sinking", women are immured in it. "Feminization of agriculture" may sound like women have arrived, but the truth is that on their slender shoulders rest the food security of the household, for which they have neither the means to enhance production nor the status and authority for being the mainstay of its subsistence' (Krishna Raj 2007: xiii-xiv).

2 The estimates refer to the principal and subsidiary status of the workers. The proportion of female workers in 2007-08 was slightly lower than what was observed in 2003-04 (Himanshu 2011). Recent evidence, however, suggests that not all women find remunerative jobs in agriculture, and that women are no longer prepared to work at very low wages (Unni and Ravindran 2007; Rangarajan et al. 2011).

3 This is somewhat similar to what has been observed in the case of class identities in rural areas (Basole and Basu 2011: 56).

4 According to Vaidyanathan (2006), the grim situation is not so much due to factors like

\section{References}

Agarwal, Bina (2010) 'Rethinking Agricultural Production Collectivities', Economic and Political Weekly 45:9: 64-78

Agarwal, Bina (2003) 'Gender and Land Rights Revisited: Exploring New Prospects via the State, Family and Market', Journal of Agrarian Change 3.1 and 3.2: 184-224

Agarwal, Bina (1994) A Field of One's Own: Gender and Land Rights in South Asia, New Delhi: Cambridge University Press

Basole, Amit and Basu, Deepankar (2011) 'Relations of Production and Modes of Surplus Extraction in India: Part I - Agriculture', Economic and Political Weekly 46.14: 41-58

Himanshu (2011) 'Employment Trends in India: A Re-examination', Economic and Political Weekly 46.37

Kishor, S. and Gupta, K. (2009) Gender Equality and Women's Empowerment in India, National Family Health Survey (NFHS-3), Mumbai: Indian Institute of Population Studies

Krishna, Sumi (ed.) (2007) Women's Livelihood Rights: Recasting Citizenship for Development, New Delhi: Sage Publications

Krishna Raj, M. (2007) 'Introduction', in M. Krishna Raj (ed.), Gender, Food Security and Rural Livelihoods, Kolkata: Stree: xiii-xx inadequate price support, low public investment, and declining size of landholdings, plus sub-normal rainfall in large parts of the country. Rather, the critical issue is about the composition of investment that would help 'improve productive potential of land and water resources already under use' (p. 4013).

5 In 2005-06, marginal and small farmers accounted for 83 per cent of the operational holdings and 41 per cent of the operated area. Small size in itself is a major disadvantage since it reduces the farmer's ability to make large investments, or gain from economies of scale, or have the necessary bargaining power in markets and with service agencies.

6 The recent evidence from the National Family Health Survey (2005-06) in India indicated that women's control over income and decision-making processes, singly or jointly with men, has brought relatively better outcomes with respect to the health and nutritional outcomes of children (Kishor and Gupta 2009). The difference, however, was found to be marginal.

Krishna Raj, M. and Shah, A. (2004) Women in Agriculture, New Delhi: Academic Foundation

Meinzen-Dick, R.; Behrman, J.; Menon, P. and Quisumbing, A. (2010) Gender: A Key Dimension Linking Agricultural Programs to Improved Nutrition and Health, 2020 Conference Brief 9, Washington DC: International Food Policy Research Institute

NCEUS (National Commission for Enterprises in the Unorganised Sector) (2010) Report on Conditions of Work and Promotion of Livelihood in the Unorganised Sector, New Delhi: Academic Foundation

Planning Commission (2011) Twelfth Plan Working Group on Disadvantaged Farmers, Including Women, New Delhi: Planning Commission

Rangarajan, C.; Kaul, P.I. and Seema (2011) 'Where is the Missing Labour Force?', Economic and Political Weekly xlvi.39

Shah, Amita (2007) 'Agriculture Diversification and Poverty Reduction: Mainstreaming Women', in M. Krishna Raj (ed.), Gender, Food Security and Rural Livelihoods, Kolkata: Stree: 73-95

Shah, Amita (2005) 'Rural Women and Agricultural Change in India', in Ramesh Chand (ed.), India's Agricultural Challenges: Reflections on Policy, Technology and Other Issues, 
New Delhi: Centre for Trade and

Development (CENTAD): 227-57

Shah, Amita and Kumar Roy, Anil (2012)

Liberalisation and Trade Reforms in Indian

Agriculture: Impacts on Women, Food Security and

Livelihoods, GIDR Occasional Paper 1,

Ahmedabad: Gujarat Institute of Development Research

Shah, Amita and Pattnaik, Itishree (forthcoming) 'Agricultural Growth in Recent Decades in India: Bridging the Gendered Gap in Nutrition', in Suneetha Kadiyala, Stuart Gillespie and Sukhadeo Thorat (eds),
Agriculture and Nutrition Linkages in India, New Delhi: International Food Policy Research Institute (IFPRI)

Unni, J. and Ravindran, G. (2007) 'Growth of Employment (1999-2000 to 2004-05): Illusion of Inclusiveness', Economic and Political Weekly 42.3

Vaidyanathan, A. (2006) 'Farmers' Suicides on the Agrarian Crisis (commentary)', Economic and Political Weekly 41.34

Vepa, S. (2005) 'Feminisation of Agriculture and Marginalisation of their Economic Stake', Economic and Political Weekly 40.25 